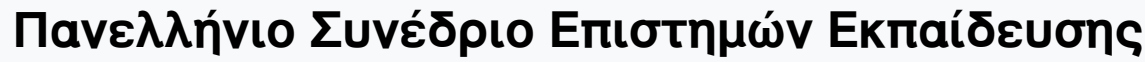

Tóp. 9 (2019)

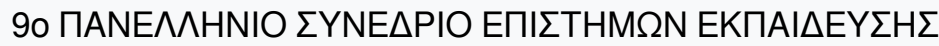

ISSN: 2529-1157

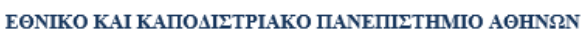
ПРОГРАММА ЕІАIKHЕ АГ ГГНУ

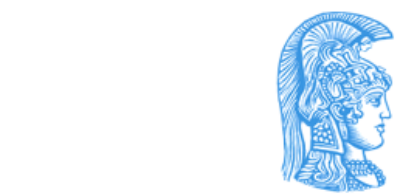

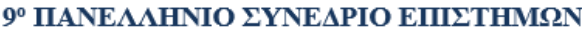
EKIIAI $\triangle E Y \Sigma H \Sigma$

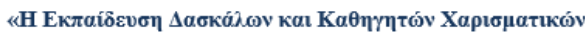

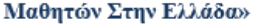

\section{ADHD and depression: Comorbidity and Therapeutic Approaches in Children}

Evangelia V. Karanana, Efthimios V. Karananas

doi: $10.12681 /$ edusc.3121

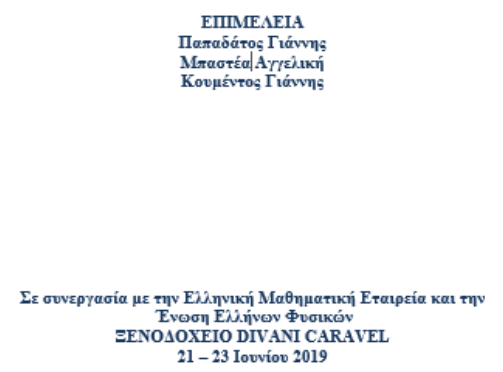

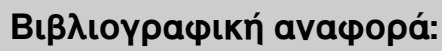

Karanana, E. V., \& Karananas, E. V. (2020). ADHD and depression: Comorbidity and Therapeutic Approaches in

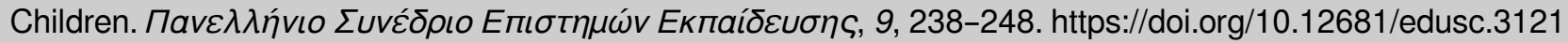




\title{
ADHD and depression: Comorbidity and Therapeutic Approaches in Children
}

\author{
Evangelia V. Karanana - Primary school teacher/ Special education teacher \\ evangeliakaranana@gmail.com
}

Efthimios V. Karananas- Primary school teacher/ Special education teacher

ekarananas@gmail.com

\begin{abstract}
The aim of thie study is to explore the case of children and adolescents with ADHD and depression. Firstly, the conceptual definition of ADHD and its characteristics are presented. Then comorbidity between ADHD and depression is discussed. In particular, it is examined when this comorbidity occurs, under what circumstances and its justification. In addition, the types of treatment approaches and how the family and school can contribute are presented. Finally, conclusions are made to strengthen the belief of self-efficacy of children-students in order to cope with depression.
\end{abstract}

Keywords: ADHD; depression; comorbidity; children and adolescents

\section{Introduction}

Attention-Deficit Hyperactivity Disorder (ADHD) is a major disorder occurring in childhood, which can continue during puberty and adulthood. ADHD records high percentages among the population. In the USA 9.5\% of people aged 4 to 17 has $\mathrm{ADHD}$, and its appearance has been increasing in the past 20 years (Visser at el, 2010).

This disorder has a number of symptoms, including difficulty in focusing and attention, difficulty in behavioral control and hyperactivity, making it difficult to perform tasks, concentrating, communicating with other children or adults, and developing social relationships. ADHD often occurs in co-morbidity with other diseases, one of which is depression.

\section{Conceptual identification and ADHD features}

Historically, the origin of the concept was based on the idea that some behavioral disorders were due to brain damage and the term "minimal brain dysfunction" was 
used (Greydanus, Pratt \& Patel, 2007). Then, in the Diagnostic and Statistical Manual of the US Psychiatric Society at the heart of the disorder analysis, focusing on behavioral level instead of focusing on brain dysfunction was put forward, as clinical studies showed that a very large percentage of children in need of psychiatric help showed hyperactivity. Therefore, the disorder was now referred to as "childhood hyperactivity response", according to DSM-II. In the third edition of the US Medical Manual (DSM-III), focus is shifted from hyperactivity to the lack of attention and focus, and the disorder is renamed "attention deficit disorder," while in Europe the reference continues to be hyperactivity. Upon revision of the standard in the United States, hyperactivity is recurrent in the disorder, with the term "attention deficit hyperactivity disorder" (DCM-III-R). In the fourth and most recent edition, ADHD belongs to the "attention deficit disorder and disruptive behavior disorders" (DCMIV).

In order to diagnose ADHD, two sets of criteria have been identified, such as: (National Institute for Health \& Clinical Excellence (2009, pp. 18-19),

\section{Either A or B.}

\section{A. Missing attention}

Six or more symptoms remain for at least 6 months to an extent that is inappropriate and inconsistent with the developmental level. Frequently fail to pay close attention to details or make careless mistakes in school, work or other activities. It is often difficult to keep track of work or game activities. They often do not seem to hear when someone speaks. They often do not follow the instructions, do not finish schoolwork, jobs or other tasks (not due to objections or inability to understand the instructions). They often have difficulty in organizing tasks and activities. Frequently avoid, dislike or are reluctant to perform tasks that require a lasting mental effort. Often lose things that are necessary for work or activities. They are often easily detached from external stimuli. They are often forgotten in everyday activities.

\section{B. Hyperactivity - impulsivity}

Six or more symptoms that persist for at least 6 months to an extent that is inappropriate and inconsistent with the developmental level.

Hyperactivity: They often nervously hand their hands. They often get up from their position either in the classroom or elsewhere where they should stay sitting. They often run or climb when it is inappropriate (respectively: feelings of anxiety in young or adult). They often have difficulty playing or enjoying leisurely activities. They are often "on the go". They often speak too much.

Progression: They often give reckless answers before the questions are completed. They are often difficult to wait for the turn. They often interrupt or interfere with others (for example, in discussions or games)

2. Some symptoms of hyperactivity, impulsivity and carelessness that cause impairment of functionality were recorded before the age of 7 years.

3. Some costs (rebates) due to the symptoms were in two or more environmental contexts (for example, at school and at home). 
4. There must be clear indications of a significant burden on social, school or job function.

5. Symptoms do not only occur during a widespread developmental disorder, schizophrenia or other psychotic disorder. Symptoms are not better explained by another mental disorder (for example, mood disorder, anxiety disorder, or personality disorder).

Preschool children have more severe symptoms and disorders than children identified later, as according to the study by Angold et al. (as reported by LaForett, Murray \& Kollins, 2008), 15\% of preschool children with ADHD have been suspended from pre-school or day care, creating a significant burden on parents, as they have fewer options for childcare by parents of school-aged children.

Another issue concerns the development of the child with ADHD in different areas of life, such as general social behavior, psychological profile, professional development, delinquency, and so on.

According to the study by Mannuzza et al. (1991), adult men diagnosed as hyperactive in childhood experienced significantly higher rates of attention deficit disorder (43\% vs. $3 \%$ of the control population), anti-social behavior (38\% vs $8 \%$ of the control population) and drug use (10\% versus $1 \%$ of the control population), and in the Taylor et al. (1996) finds that child hyperactivity is a risk factor for their later development, with a high probability of psychiatric diagnosis, violence, poor social adaptation and other antisocial behaviors.

\section{Comorbidity between ADHD and depression}

In the research by Ehsan et al. (2009), 5.8\% of children with ADHD in the sample had comorbidity with depression. However, Alessi \& Magen (1988) reported a correlation between attention deficit hyperactivity disorder and mood disorders in children with non-bipolar major depression and dysthymia, while in the study by Weinberg et al. (1989) records that about $30 \%$ of the pupils in the sample had both depression and hyperactivity, who also had the most problematic behavior, followed by pupils with depression without hyperactivity and with pupils without depression but with hyperactivity presenting the least problematic behavior.

A dimension of ADHD comorbidity with depression is related to the degradation of the development of the executive functions and a series of interrelated capacities based on the frontal cortex regions and related connections in the chamber and basal ganglia (Schachar, Tannock, \& Logan, 1993) ie vascular lesions that have been shown to be associated with depression (Xakardaki et al., 2013). Of course, another dimension of this interconnection should be emphasized: as the child has problems in the executive function in his various skills, such as self-knowledge, inhibition, visual memory, hence neuropsychological dysfunction due to brain development problems Nigg et al., 2005), the perception of these problems creates a feeling of impotence, greatly reduces self-esteem and leads to depression.

The medical dimension should not be ignored, as axial and magnetic tomography of the brain found that in children with ADHD the brain develops normally, but its growth is delayed by about three years (Shaw et al., 2007). The study of Shaw et al. 
(2012) shows that the brain cortex in children with ADHD has a developmental delay, especially in areas of the brain that are concerned with attention, thought and planning. Therefore, ADHD can be described as a neurobiological disorder, related to the structure and function of certain points of the brain. However, focusing exclusively on the medical aetiology of ADHD removes the potential of a comprehensive and multidimensional intervention and focuses on its pharmaceutical treatment.

At this point we should mention a basic dimension of ADHD co-morbidity with depression, which relates to the justification of functional disorders. Contrary to the case of Werry et al. (1987) that lower children's intelligence could explain functional disorders associated with ADHD in the study by Lahey et al. (2004), this causality was not found, as almost all of the children who met the full ADHD criteria continued to show significant functional disorders over the years of the control group children with the same level of intelligence over the coming years. However, as either the educator or parents or the wider social environment have the perception that the child's functional disorders are due to his / her lower intelligence, they automatically attribute a characteristic to the child, which features as an assessment mechanism in terms of capabilities of the child and at the same time as a stigmatizing mechanism.

At the same time, however, the perception that symptoms are an indication of low intelligence also acts as a stigmatizing mechanism. The stigmatization of the person who has a malfunction is due to the fact that in society the perception that this person does not have the characteristics of a "normal" person (Goffman, 1963), so his malfunction, his "deficit" its central feature: on the basis of this "dysfunction" is categorized and based on this "deficit" form its "normal" relations with him.

In addition to the above causes, ADHD's comorbidity with depression can also have organic causes that are related to the child's diet. In particular, according to Torren et al. (1996), children with ADHD record lower zinc levels than children with the same demographic profile without ADHD, which is associated with an increase in the likelihood of depression, as shown by studies (for example: Ranjab et al., 2013; Petrilli et al., 2017), low zinc levels have statistically significant positive correlation with the occurrence of depression.

Also, in addition to zinc, foods with high trans fat and other aggravating foods create high levels of cortisol, which among other things causes weakening of short-term memory. Children with ADHD often experience high levels of cortisol and low levels of serotonin and dopamine. Their low levels are associated with depression (Ottoboni, 2003), therefore diet is the cause of comorbidity.

One of the most important elements of depression of ADHD children is that these children have a problem in both the recognition and management of their anger, with the result that anger is internalized and that the child does not know how to respond to that particular feeling. Therefore, it is necessary to apply both anger and therapists activities to recognize anger, learn to postpone the response to anger, and breathing exercises (Smita et al., 2014). 


\section{Therapeutic Approaches in Children with ADHD and Depression}

There are many types of approaches for children with ADHD. One of the most widely used is behavioral approaches that aim to change the social and physical environment to alter the behavior of the child with ADHD. There are a number of types of behavioral approaches, such as parent training, cognitive behavioral therapy, classroom behavioral interventions, and so on.

Parental education, as a therapeutic intervention, has strong theoretical documentation for both pre-school and school-age children. As far as pre-school children are concerned, parental education is judged to be particularly important and has been recorded as being more effective at pre-school age than in school age. The effectiveness of parent education can be analyzed in two areas of reference: the first field is for children with ADHD and the second field is for the parents themselves.

s children, provision of education to parents of children with ADHD of this age has the potential to prevent the development of secondary school-related disorders such as school failure, school stress, difficulties in dealing with other students.

As far as the field of parenting is concerned, the provision of education teaches them how to recognize and manage the high parental anxiety and low self-esteem associated with the high demands of a child, especially preschool age.

The interconnection of these two fields is dynamic, in the sense that, as shown in studies (for example: Keown and Woodward, 2002), poor parenting management strategies such as anxious mothering, inadequate parental communication, and reduced encouragement have positive correlation with the increase in symptoms and with problematic behavioral outcomes.

One of the programs that apply to parent education is the Triple P Positive Parenting Program, developed by Matthew Sanders, initially as a program involving parents of preschool children with behavioral problems, and then evolved as a preventive intervention program (Vlachogianni \& Angeli, 2014). The program is implemented in social learning-based therapy sessions designed to promote the ability and development of children, teach parents to manage bad behavior and generalize skills using role models and games. As demonstrated by the Bor, Sanders \& Markie-Dadds (2002) study, the implementation of the Triple P Positive Parenting Program in preschool children whose parents recognized at least six DSM-IV symptoms of lack of attention and hyperactivity provided positive results. parents' assessment of child disintegration and other ADHD symptoms improved by $80 \%$ compared to the control group.

Another program is Parent-Child Interaction Therapy (PCIT), which provides sessions where parents are advised to interact with the child. The PCIT program is a psychological intervention for children with behavioral problems, with significant similarities to those with ADHD, and has therefore been applied to children with ADHD and their parents, with positive results in parental assessments, but also improving evaluations of teachers in the classes of children (Funderburk et al, 1998). 
At this point it should be mentioned that the treatment of ADHD that is combined with depression can only have the pillar of the family, as one of the causes of the spread of ADHD is the changes in the social structure and functioning of the family, less and less involvement of parents - and especially of the father - in the care and overall education of children, with increased cases of family dysfunction and increased cases of parental psychopathology, phenomena leading to an increase of childhood depression rates for children, all the more so for children with ADHD (Hanna, 2009).

One of the characteristics of ADHD students is that while they have the ability to pay special attention to certain specific activities of interest to them, or they are very scared, they have considerable difficulty in maintaining an adequate focus on many other activities (Brown, 2009). Therefore, one of the main issues of classroom intervention should be to highlight this ability that students have and not to concentrate on what they can not do. Reproduction of the idea of impotence by teachers consolidates depression as the students with ADHD depression self-confirm that they are incapable of doing so, especially if it is based on medical justification, so they feel they are being asked to do something which for medical reasons are unable to do. Thus, while the students create a "defensive shield" (Schultz, 2011), hiding behind the medical justification of the malfunction, at the same time they continue to experience rejection, marginalization and stigmatization, thus depressing to strengthen and acquire fixed characteristics . In contrast, if depression is thought to be mild, ADHD treatment can lead to depression of depressive symptoms, because mild depression may have developed as a result of life complications with un-treated ADHD (Albrecht, 2010). Therefore, the educator should focus on infusing the students with ADHD and depression with the belief that they have the potential to intervene actively in the malfunction.

In order for interventions to be effective, they should focus on strengthening the selfefficacy and place of control of children with ADHD, especially when ADHD is accompanied by depression. Through empowerment of belief in these two axes, children are activated, active, and can fight off depression while at the same time realizing the real dimension of the difficulties they face.

\section{Conclusions}

This work has shown that ADHD is a major disorder that affects a number of roles in the child's life, such as the formation of personal and social relationships, education, professional development, and so on. Although in ADHD there is a medical aetiology, however, it should be managed in complex terms, including medical, social and family axes.

Both the educator and the parent should focus on how to strengthen the self-efficacy belief and place of control of children-students in order to actively cope with depression and to push the children to intervene, as much as possible, to the malfunction themselves.

An important element for teachers is to shape the school climate towards the pupil with ADHD. According to a Coles study (2009), the first challenge faced by teachers is personal. They must maintain order, remain impartial, and remain enthusiastic, patient and respectful. The teacher should make sure that children with learning 
disabilities have equal opportunities and help them achieve their full potential, but not at the expense of other children, which can prove to be a real challenge. It must be ensured that there is no undue preference for the children with ADHD over other children, but not vice versa, as it is important that the teacher does not present personal prejudices. Teachers should be fair in the classroom environment so that knowledge is disseminated to all students, of course always taking into account their capabilities and abilities.

The creation and maintenance of an inclusive school community requires an emphasis on a sense of belonging and effective participation in the creation of alliances and partnerships and the provision of mutual, emotional and technical support to all members of the community (Sands, Kozleski \& French, 2000 ).

The same applies to parents: the more the parents perceive the ability to manage children with ADHD and the more they eliminate the social stereotypes of "disability", "deficit" and malfunction, the more effectively they can help children to take on an active role that will enable them to shape their future life according to their abilities and the efforts they will make. 


\section{Bibliography}

Alberty, I.P., \& Munafo, M. (2008). Key concepts in health psychology. London: Sage Albrecht, A.T. (2010). 100 questions and answers about adult attentiondeficit/hyperactivity. Sudbury, MA: Jones and Bartlett

Alessi, N.E. \& Magen, J. (1988). Comorbidity of other psychiatric disturbances in depressed, psychiatrically hospitalized children. Am J Psychiatry, 145, 1582-1584

Biederman, J., Newcorn, J., \& Sprich S . (1991). Comorbidity of ADHD with conduct, depressive, anxiety, and other disorders. Am J Psychiatry, 148, 564-577

Bor, W., Sanders, M.R. \& Markie-Dadds C. (2002). The effects of the Triple PPositive Parenting Program on preschool children with co-occurring disruptive behavior and attentional/ hyperactive difficulties. J Abnorm Child Psychol., 30:571587

Brown, T.E (2009). Developmental Complexities of attentional disorders. In T.E. Brown (ed.), ADHD Comorbidities: Handbook for ADHD Complications in Children and Adults (pp 3-22.) Washington DC: American Psychiatric Publishing

Coles, B.(2009). Top challenges teachers face in special needs inclusive classrooms, Helium, 1-7,

Ehsan, M.G., Asmaa, A.A., Maged, E., Salem, E. \& Adel, S. (2009).Study of some perspective of attention deficit hyperactivity disorder in children. Current Psychiatry, 16(4), 403-409

Funderburk. B.W., Eyberg, S.M., Newcomb, K, McNeil, C.B., Hembree-Kigin, T \& Capage, L. (1998). Behavior problem children: maintenance of treatment effects in the school setting. Child \& Family Behavior Therapy, 20(2), 17-38

Greydanus, D.E, Pratt, H.D., Patel, D.R. (2007). Attention deficit hyperactivity disorder across the lifespan: the child, adolescent and adult. Dis Mon, 53, 70-131 
Hanna, N. (2009). Attention Deficit Disorder (ADD) Attention Deficit Hyperactive Disorder (ADHD). Is it a product of our modern lifestyles? Americal Journal of Clinical Medicine, 6(4), 22-28

Keown, L.J. \& Wooward, L.J. (2002). Early parent-child relations and family functioning of preschool boys with pervasive hyperactivity. J Abnorm Child Psychol, $30,541-553$.

LaForett, D. R., Murray, D. W., \& Kollins, S. H. (2008). Psychosocial treatment for preschool-aged children with Attention-Deficit Hyperactivity Disorder. Disabilities Research Reviews, 14, 300-310.

Lahey, B.B., Pelham, W.E., Loney, J.,Kipp, H., Ehrhardt, A., Lee, S.S.Willcutt, E.G., Hartung, C.M., Chronis, A. \& Massetti, G (2004). Three-year predictive validity of DSM-IV attention deficit hyperactivity disorder in children diagnosed at 4-6 years of age. Am J Psychiatry, 161 (11), 2014-2020

Lichter P. (1993). The Washington State ADHD Handbook: A Guideline for Building Administrators and Educators. Olympia, Wash: State of Washington, Department of Education

Mannuzza, S., Klein, R.G., Bonagura, N., Malloy, P., Giampino, T.L. \& Addalli, K.A. (1991). Hyperactive boys almost grown up: replication of psychiatric status. Arch Gen Psychiatr, 48, 77-83

Nigg, J.T., Willcutt, E.G., . Doyle, A.E. \& Sonuga-Barke, E.J.S. (2005).Causal Heterogeneity in Attention-Deficit/ Hyperactivity Disorder: Do We Need Neuropsychologically Impaired Subtypes?. Biol Psychiatry, 57, 1224-1230

Ottoboni, F. (2003).Can attention deficit-hyperactivity disorder result from nutritional deficiency?. Journal of American Physicians and Surgeons, 8(2), 58-60

Petrilli, M.A., Kranz, T.M., Kleinhaus, K., Malaspina, D. (2017). The emerging role for zinc in depression and psychosis. Front Pharmacol., 8, 414. 
Ranjbar, E., Kasaei, M.S., Mohammad-Shirazi, M.M., Mohammadi, R. (2013). Effects of zinc supplementation in patients with major depression: a randomized clinical trial. Iran J Psychiatry, 8(2), 73-79.

Sands, D. J., Kozleski, E. B. \& French, N. K. (2000). Inclusive education for the 21 st century. Mason, $\mathrm{OH}$ : Cengage Learning

Schachar, R., Tannock, R. \& Logan, G. (1993): Inhibitory control, impulsiveness and attention deficit hyperactivity disorder. Clin Psychol Rev., 13, 721-739

Schultz, J.J. (2011). Nowhere to hide: why kids with adhd and ld hate school and what we can do. San Francisco: Jossey Bass

Shaw, P., Eckstrand, K., Sharp, W., Blumenthal, J. \& Lerch, J.P. (2007). Attentiondeficit/hyperactivity disorder is characterized by a delay in cortical maturation. Proc Natl Acad Sci., 104(49), 19649-19654.

Shaw, P., Malek, M., Watson, B., Sharp, W., Evans, A. \& Greenstein D. (2012). Development of cortical surface area and gyrification in attention-deficit/hyperactivity disorder. Biol Psychiatry, 72(3), 191-197

Smitha, V. S., Varghese, P.K., Dennis, D.I.M. and Vinayan K. (2014). Effect of social skill group training in children with Attention Deficit Hyperactivity Disorder. Amrita Journal of Medicine, 10(2), 1-44

Swensen, A.R., Birnbaum, H.G., Secnik, K., Marynchenko, M., Greenberg, P. \& Claxton, A. (2003). Attention-Deficit/Hyperactivity Disorder: increased costs for patients and their families. J. Am. Acad. Child Adolesc. Psychiatry, 42(12) 14151423 ,

Taylor, E., Chadwick, O., Heptinstall, E. \& Danckaerts, M. (1996). Hyperactivity and conduct problems as risk factors for adolescent development. J Am Acad Child Adolesc Psychiatry, 35, 1213-1226

Toren, P., Eldar, S., Sela, B.-A., Wolmer, L., RWeitz, R., Inbar, D., Koren, S., Reiss, A., Weizman, R. \& Laor, N. (1996). Zinc deficiency disorder in attentiondeficit hyperactivity. Biol Psychiatry, 40, 1308-1310 
Visser, S.N., Bitsko, R.H., Danielson, M.L., Perou, R., \& Blumberg, S.J. (2010). Increasing prevalence of parent-reported attention-deficit/hyperactivity disorder among children -United States, 2003 and 2007. Morbidity and Mortality Weekly Report, 59, 1439-1443.

Weinberg, W.A., McLean, A., Snider, R.L, Nuckols, A.S., Rintelmann, J.W., Erwin, P.R \& Brumback R.A. (1989). Depression, learning disability, and school behavior problems. Psychol Rep., 64(1), 275-83.

Vlachogianni, A. \& Angeli, K. (2014). Parental involvement programs. CognitiveBehavioral Research \& Treatment, 1 (1), 41-53

Xakardaki, A., Kovari, Giannakopoulos, P. \& Bouras, K. (2013). Documents from magnetic resonance imaging studies in case of depression. Neurology, 22 (3), 15-19 